\title{
Immersive Experience Impact on Students’ Understanding of Design
}

\section{Ms. Antonette T. Cummings P.E., Purdue University}

Antonette Cummings is a Ph.D. student in Engineering Education at Purdue University. She holds an M.S. in Mechanical Engineering from the University of Texas at Austin.

\section{Dr. Carla B. Zoltowski, Purdue University, West Lafayette}

Carla B. Zoltowski, Ph.D., is Co-Director of the EPICS Program at Purdue University. She received her B.S. and M.S. in electrical engineering and Ph.D. in engineering education, all from Purdue University. She has served as a lecturer in Purdue's School of Electrical and Computer Engineering. Dr. Zoltowski's academic and research interests include human-centered design learning and assessment, service-learning, ethical reasoning development and assessment, leadership, and assistive technology.

\section{Ms. Ming-Chien Hsu, Purdue University, West Lafayette}

Ming-Chien Hsu is a doctoral candidate of Engineering Education at Purdue University. She was an electrical engineer working on semiconductor devices before stepping into the realm of education research. Her current research explores and characterizes learning experiences in engineering such as design and interdisciplinary learning.

\section{Dr. Monica E Cardella, Purdue University, West Lafayette}

Monica Cardella is an Associate Professor of Engineering Education at Purdue University. She teaches design to first-year engineering students at Purdue as well as an upper-level design course for seniors and graduate students. Her research focuses on the development of engineering thinking skills (operationalized as design thinking, mathematical thinking, and the interplay between the two) in children as young as 4 years old as well as older "children" (i.e. undergraduate students).

\section{Dr. William C. Oakes, Purdue University, West Lafayette}

William (Bill) Oakes is the Director of the EPICS Program and Professor at Purdue University. He is one of the founding faculty members in the School of Engineering Education with courtesy appointments in Mechanical, Environmental and Ecological Engineering as well as Curriculum and Instruction in the College of Education. He has received numerous awards for his efforts at Purdue including being elected as a fellow of the Teaching Academy and listed in the Book of Great Teachers. He was the first engineer to receive the U.S. Campus Compact Thomas Ehrlich Faculty Award for Service-Learning. He was a co-recipient of the U.S. National Academy of Engineering's Bernard Gordon Prize for Innovation in Engineering and Technology Education and the recipient of the ASEE Chester Carlson Award for Innovation in Engineering Education. He is a fellow of ASEE and the National Society of Professional Engineers (NSPE). 


\title{
Immersive Experience Impact on Students' Understanding of Design
}

\begin{abstract}
To promote undergraduate students' understanding of a human-centered design process, we conducted an engineering design course over a three week summer session which included an immersive experience at an outdoor center that hosts camps for children with disabilities. There were 13 participants in the course. We measured the participants' understanding of design by categorizing their responses to a soapbox derby car design task at the beginning and end of the course. We determined that the participants generally made progress toward empathic design, where both their understanding of the design process and their understanding of the stakeholders improved simultaneously. We recommend the inclusion of short course immersive experiences such as this for teaching human-centered design.
\end{abstract}

\section{Introduction}

Design is a central and distinguishing activity of engineering ${ }^{[1]}$ and one of the core criteria for evaluating and accrediting engineering programs ${ }^{[2]}$. In today's globally competitive economy, it is more important than ever to develop effective design skills within the undergraduate years ${ }^{\text {[3], }}$

${ }^{[4]}$. Furthermore, developing a human-centered approach to design is vital to appropriately preparing graduates for the globally competitive workplace ${ }^{[5]}$. In response, design education has received increased attention within the curriculum, which has motivated the creation of a variety of courses, course activities and multidisciplinary programs focused on the development of engineering products and solutions. One approach is engaging multidisciplinary teams of students in community-based design projects.

Our community engagement program, EPICS, provides opportunities for vertically-integrated, multidisciplinary teams to develop design knowledge and skills. EPICS has intentionally focused on long-term partnerships and local community partners because of the learning benefits afforded through the ability to engage with community partners more regularly. Previous studies have indicated that understanding the nature of those interactions between students and their community partners and other stakeholders is important ${ }^{[6],[7]}$. Research suggests that critical experiences, where design assumptions are confronted, and immersive experiences are needed to develop more comprehensive ways of understanding design ${ }^{[8]}$.

This past summer, EPICS offered an immersive design experience to a group of 13 students (12 undergraduate, 1 graduate) from a variety of majors. Another publication provides a broader description of this course and includes data from the participants' reflections ${ }^{\text {[9] }}$. The design team's goal was to make the camp more accessible to children with physical disabilities through two projects: the design of an accessible tree house and the adaptation of a sailboat to allow control of the steering through a switch (e.g., puff and sip or joystick). The students completed one week on campus, then traveled to the camp for children with disabilities for a week. During this week, the students ate meals and attended various activities with the campers and met with various stakeholders. They also involved the campers in the design of the tree house. After spending a week at camp, the students returned to campus to continue work on the designs. 
This paper briefly describes the immersive learning experience and examines the impact that an immersive community engagement experience has had on student learning of design, addressing the research question of: can a week-long immersive design experience impact students' understanding of design?

\section{Conceptual Framework}

This project was informed by and based on previous research that has looked at several concepts: design, differences between experts and novices as they practice design, and types of experiences that impact students' understanding of design.

What is an immersive experience? IDEO presents a research method of "in-context immersion", where designers should "[meet] people where they live, work, and socialize... Try to do what your constituents do and talk to them about their experience of life in the moment" "10]. IDEO lists several tips about the benefits of an immersive experience: 1) "what people say (and think) they do and what they actually do are not always the same thing" 2) "putting yourself in someone's shoes enables you to get beyond what people say to what they think and feel" and 3) "deep immersion shows commitment and staying power". The immersion method for gathering information about people's wants and needs is a viable alternative to group interviews with child participants or expert interviews. This method is part of a larger human-centered design process, which we discuss more in the following paragraphs.

Ultimately, the goal of teaching human-centered design is for designers to be truly empathic. One approach in developing empathy in students was to ask students to design for aliens in order that the designers would not make assumptions according to their own preconceptions and experiences ${ }^{[1]}$. Another approach is service-learning. Human-centered design has been employed in the service-learning context of EPICS ${ }^{[12]}$ and includes undergraduates from a variety of majors.

The design process taught in EPICS, while iterative, has the main steps: Project Identification, Specification Development, Conceptual Design, Detailed Design, Delivery, Maintenance, Retirement/Redesign. At the center of the design process are Stakeholders, with whom the designers should be communicating at every step of the design process ${ }^{[12]}$.

How can we assess a person's understanding of design? We highlight in this paper one framework for comparing beginner designer and informed designer behaviors and another phenomenographic framework for human-centered design that simultaneously considers design as an iterative process and the extent of inclusion of the users. For this work, we primarily use the phenomenographic framework for human-centered design because it has been articulated as a series of distinct stages and therefore it lends itself to quantitative analysis, which in turn supports the measurement of the impact of this immersive course. Both frameworks inform the rubric that is in development to assist others in categorizing the design tasks.

Much research over the past 20 years has explored expert-novice differences in design behavior

[13], [1]. Recently, Crismond and Adams ${ }^{[14]}$ have added to the discussion by synthesizing 
published literature on teaching and learning design in order to identify patterns of behavior between "beginning" and "informed" designers. They identified nine design strategies where "informed" designers differ from "beginning" designers: 1) understand the challenge 2) build knowledge 3) generate ideas 4) represent ideas 5) weigh options and make decisions 6) conduct experiments 7) troubleshoot 8) revise/iterate and 9) reflect on the process. The authors provide teaching strategies to move learners from beginning to more informed designers. While this framework is difficult to transform into a quantitative measure, it is still valuable for analyzing the design task data. For example, Crismond and Adams recommended teaching strategies for "building knowledge", which include "do studies/research on users" in order to "enhance background knowledge, and build understandings of users, mechanisms, and systems". This framework for behavior of an informed designer closely resembles human-centered design because of the emphasis on knowing the user.

The main emphasis of human-centered design is that engineering design is an iterative process that is centered on constant communication with the stakeholders of the project. Zoltowski ${ }^{[15]}$ has contributed to the body of literature on expert-novice differences in engineering through her focus on human-centered design. In her phenomenographic study, Zoltowski identified seven distinct ways that students experience (and understand) human-centered design and she presented these experiences as a hierarchy of stages of increasing comprehensiveness ${ }^{[8]}$. The learning experiences of designers appear to increase both the designers' understanding of design and the designers' understanding of the users and stakeholders simultaneously, rather than gaining a full understanding of each separately. These seven ways of experiencing design are listed as categories, shown in Table 2, and are the basis of the subsequent data analysis of this paper.

There are educational implications from the phenomenographic study of human-centered design, including the experience with real users (a critical experience) and reflection on the design process ${ }^{[16]}$. This immersive course is an attempt at providing a critical experience, with perhaps an economic and time-commitment advantage over a summer-long internship or a global design experience.

After considering the different ways that students understand human-centered design, and considering different approaches for providing learning experiences that help students learn human-centered design, we need appropriate assessment methods to measure students' understanding of human-centered design if we are going to answer the question: can a week-long immersive design experience impact students' understanding of design?

\section{Instrument}

Our research group previously developed and pilot-tested a design task as a tool for eliciting a student's understanding of human-centered design ${ }^{[17]}$. In another publication, we show the use of this design task for first-year engineering students as further validation of the design task ${ }^{[18]}$. The design task is attached in Appendix B. The design task provides a three paragraph description of the scenario, including the dilemma of whether to provide a real steering experience to a child with physical or cognitive disability with adult override capability. The design task asks for a term-long plan (students at semester-based universities develop a semester- 
long plan; students at quarter-based universities develop a quarter-long plan) to address the project. The design task includes a table prompting students to describe, in detail, the activities to be completed during this term leading up to delivery of a finished project and include the specific design decisions they would make and the different roles their teammates would take. Students complete Table B1 by listing (1) the activities that would need to be completed, (2) the resources (people or otherwise) that would be involved in completing each activity, (3) how that resource would be involved, and (4) for what purpose the students would complete that particular activity. Students are also given a blank sheet of paper to optionally create a visual representation (flow chart, flow diagram, Gantt chart, or other picture) to show the sequencing and/or relationships of the activities or any other information that would benefit them. After completing the table, students are also asked to respond to five open-ended questions (B1-B5 in Appendix B) that further probe their conceptions of and approaches to design, as well as personal experiences that influence their approach to design. The soapbox derby design task has been used, unchanged, in this work as the tool for measuring the impact of the immersive experience on students' understanding of design.

\section{Participants}

The main data source for investigating the impact of this immersive experience is the soapbox derby design task responses from the 13 participants enrolled in the course. Demographics of the participants are provided in Table 1 below. Age, major, and number of semesters in our community engagement program were asked via survey, attached in Appendix A; the first author supplied gender but did not wish to pre-suppose race classification. Twelve of the 13 participants submitted pre-camp and post-camp soapbox derby design task responses and reflection questions. The reflection questions, B6 and B7 in Appendix B, supplement the precamp and post-camp comparison of the design task responses.

Table 1. Demographics of participating students.

\begin{tabular}{|l|l|l|l|l|}
\hline Pseudonym & Age & Gender & Major & $\begin{array}{l}\text { Semesters Previously } \\
\text { Enrolled in EPICS }\end{array}$ \\
\hline CR01 & Senior & Male & Computer Science & 0 \\
\hline CR02 & Junior & Female & Mechanical Engineering & 0 \\
\hline CR03 & Senior & Female & Multidisciplinary Engineering & 0 \\
\hline CR04 & Senior & Male & Atmospheric Science & 0 \\
\hline CR05 & Graduate & Female & Industrial Design & 0 \\
\hline CR06 & Senior & Female & $\begin{array}{l}\text { Multidisciplinary Engineering \& } \\
\text { Health and Human Sciences }\end{array}$ & 5 \\
\hline CR07 & Senior & Male & Biomedical Engineering & 4 \\
\hline CR08 & Sophomore & Male & Biomedical Engineering & 0 \\
\hline CR09 & Junior & Female & Biomedical Engineering & 0 \\
\hline CR10 & Senior & Female & Biomedical Engineering & 0 \\
\hline CR11 & Sophomore & Female & Speech Language Audiology & 0 \\
\hline CR12 & Junior & Female & Biomedical Engineering & 0 \\
\hline CR13 & Senior & Female & Biomedical Engineering & 0 \\
\hline
\end{tabular}


All the participating students submitted a written application to the course, expressing some interest in community service; several had previous experience in community service through other programs. The two participants who had previous experience in EPICS would presumably recall the human-centered design process that is taught in lecture and emphasized in weekly lab meetings. One participant, a graduate student, has academic and professional design experience. Participant CR02 describes previous experience in a global design concerning confronted assumptions. We may expect (and did find in Table 3 ) a more advanced starting point for these students as compared to the others who had not been necessarily taught or had practiced a human-centered design process.

\section{Context for the Immersive Experience}

The three week, three credit-hour course in the summer consisted of three distinct phases: introduction to the human-centered design process and skill development; a week of staying at the camp to observe and interact with campers ages 8 to 13, counselors, administrators, architects, a doctor affiliated with the camp, and donors; and a week of continuing design work to present to the same stakeholders. It is noteworthy that camp was about a two hour drive from campus, so that the students stayed at camp, away from familiar surroundings, but it was not so far away as to introduce complexity and high cost in arranging travel.

In the first week, we encouraged students to consider others instead of making assumptions and to consider prior art. Firstly, the students completed a wallet design exercise, which included a "false start" of designing the ideal wallet for oneself, then partnering with another in order to design, prototype, and test the ideal wallet for someone else ${ }^{[19]}$. One innovative result from this exercise was a new wallet designed around a water bottle, according to the user's daily habits. Secondly, the students completed an observation exercise. One student moved by manual wheelchair between two buildings on campus as a simulation of moving between classes. The students noted the number and presence of assistive devices, signage, and time required for the task. Thirdly, for prior art research, the sailboat project team found designs by the Disabled Sailing Association and the treehouse project team considered ADA codes and types of physical disabilities, such as mobility, visual, and hearing impairments. Fourthly, the students interviewed a local physical education teacher who has adapted activities for children with disabilities, to include sit-volleyball and tennis-like games with larger, lighter rackets made of coat hangers and hosiery. These tasks and interviews, though, are not a substitute for immersion.

In the second week, the participants of the course were immersed in a different culture, a summer camp environment dedicated to and entirely populated with children with disabilities who are encouraged to challenge themselves in an outdoor setting. The adults at camp, including the students in this course, changed their language to say "we" and "with" instead of "that disabled child" or to say "getting sassy" instead of "cranky". The campgrounds have only ramps and no stairs. Breakfast was at 9 am because dressing routines were lengthy and tiring for many campers. No adult used a cell phone in the presence of a camper. Administrators noted especially the sadness that campers feel when they leave, because the campers say that daily life is not like camp. These patterns of behavior indicate the camper-first culture of the camp. 
The second week, the students went to camp, not as counselors but as participant-observers. The students had an orientation with administrators; the motto was "empowerment, engagement, and empathy", which includes how to speak and interact with the campers, to understand some of the campers' medical devices, and to appreciate that the counselors are well-trained on physical, emotional, and social needs of the campers. The students had several lunches and dinners with their assigned cabins, which included setting the table, serving food family-style, adapting cutlery as necessary, clearing dishes, and one Emergency Dance Party (EDP). The students observed and interacted with the campers in various activities, which included swimming, a pontoon boat ride, painting, a hike through the trees, and a scavenger hunt. The water activities provided the sailboat team some insight on existing water safety protocols, such as unbuckling seatbelts of wheelchairs while around water. The treehouse team viewed the recentlyconstructed zipline and the adapted ropes course and climbing tower. Several assumptions were confronted, such as counselors' lifting campers as needed instead of using power-assisted lifting devices; the erroneous assumption that a camper first observed in a wheelchair was unable to walk; and the assumption that all the campers used wheelchairs. The treehouse team had two rounds of soliciting campers' ideas and feedback on the perfect treehouse; one camper suggested a slide from the treehouse to the swimming hole about 400 yards away, one idea among many that the engineering students might not have suggested. A funder for the treehouse suggested access to electricity to facilitate ventilator equipment for overnight stays, a potential requirement that the students found needed negotiation between the maintainers and the donors. The stories of the campers and counselors became data in the stakeholder profiles and design specifications in the two teams' design documents. The students also presented their work to date for feedback from the stakeholders.

The third week of the course involved the students' developing and refining designs for their respective projects. The students applied engineering knowledge and design tools to communicate and down-select their recommendations. The students presented their work to the administrators and donors and proposed future work.

\section{Role of the Researchers}

The first author functioned as a teaching assistant for this course of EPICS and in two regular semester sessions of EPICS prior to that, including an ongoing soapbox derby project much like the design task in Appendix B. The third author functioned as a teaching assistant for an Introduction to Engineering course, which also teaches human-centered design outside of the service-learning context. The third author is developing a rubric for the design task to help educators use the tool in their own environment, mentioned in a later section of this paper, so the third author has reviewed hundreds of completed design tasks, mostly from first year engineering students.

The first author analyzed all of the pre-camp data first and then analyzed the post-camp data as if the two sets were not paired. The second author was the instructor for the course, and scored the design tasks by comparing the data in the design tasks to the data in Zoltowski ${ }^{[8]}$. The third author analyzed the data as pairs, with the pre-camp data in mind as she reviewed the post-camp data. The first author tended to start categorizing the data highly and then move down the categories, whereas the second and third authors tended to start at the low categories and move 
up. For the final categorization of the design tasks, the first three authors met and discussed the scoring until they reached agreement. In order to reduce bias and to follow the Category framework properly, we recommend rating pre/post data not as pairs and to start from the lower categories and move up.

\section{Design Task Administration}

The soapbox derby design task was provided to the students via email the week before the course began and submitted by the students before the first day of lecture to constitute the "pre-camp" data. The students submitted responses to the same design task on the last day of course to constitute the "post-camp" data. Additionally, the students submitted responses to the reflection questions, B6 and B7, when the instructors gave back both copies to each of the students for them to review.

\section{Analytic Approach}

We categorized the responses to the entire soapbox derby design task according to the seven phenomenographic categories developed by Zoltowski ${ }^{[8]}$; summarized descriptions are reproduced in Table 2 below. Category 1: Technology-centered is considered the least comprehensive understanding of design and Category 7: Empathic Design is considered the most comprehensive understanding of design. We refer to the numeric values of the categories throughout the paper.

Table 2. Categories of Description (Human-centered design is...) and Summary.

\begin{tabular}{|c|l|}
\hline Categories & \multicolumn{1}{c|}{ Summary } \\
\hline $\begin{array}{c}\text { Category 1: } \\
\text { Technology- } \\
\text { Centered }\end{array}$ & $\begin{array}{l}\text { Human-centered design is not human-centered, but technology-centered } \\
\text { design. The focus of the design is on the technology and solving the technical } \\
\text { problem, not on the "others" or humans. Their approach lacks both an } \\
\text { understanding of the users and an appreciation for their knowledge, } \\
\text { experiences, and perspectives. Instead of users, professors, design reviewers, } \\
\text { and those with power have voice. }\end{array}$ \\
\hline $\begin{array}{c}\text { Category 2: } \\
\text { Service }\end{array}$ & $\begin{array}{l}\text { Human-centered design is not design but service, viewing what they are doing } \\
\text { as helping or positively benefitting others but utilizing very limited, if any, } \\
\text { design methods or process to achieve that goal (e.g., needs assessment, } \\
\text { iteration, decision-making tools, convergent and divergent thinking, balancing } \\
\text { of constraints, perspective-taking, getting feedback, or prototyping). Instead of } \\
\text { using design methods or processes, the students in this category primarily } \\
\text { identified and completed tasks related the goal. }\end{array}$ \\
$\begin{array}{c}\text { Category 3: } \\
\text { User as } \\
\text { Information } \\
\text { Linear }\end{array}$ & $\begin{array}{l}\text { Stakeholders are viewed primarily as sources of information, assistance, and/or } \\
\text { support, not those whose needs should be reflected in design. This approach } \\
\text { reflects novice design skills in that information from the stakeholders is } \\
\text { incorporated to the extent that it does not make the design too messy or } \\
\text { difficult and process involves little or no feedback or iteration. }\end{array}$ \\
\hline
\end{tabular}




\begin{tabular}{|c|c|}
\hline $\begin{array}{l}\text { Category 4: } \\
\text { Keeping the } \\
\text { Users' Needs } \\
\text { in Mind }\end{array}$ & $\begin{array}{l}\text { Human-centered design is keeping the users' needs and how design will be } \\
\text { used in mind while designing. The student designers in this category gathered } \\
\text { information about the users primarily from higher level stakeholders or experts } \\
\text { versus the users themselves but did not consider broader contextual issues or } \\
\text { talk about taking their perspective. They did consider aspects of technical } \\
\text { feasibility and viability and integrated those aspects with their understanding } \\
\text { of the user to the extent that their disciplinary knowledge allowed. }\end{array}$ \\
\hline $\begin{array}{l}\text { Category 5: } \\
\text { Understanding } \\
\text { the Need in } \\
\text { Context }\end{array}$ & $\begin{array}{l}\text { Human-centered design is understanding the design in context, seeking } \\
\text { knowledge not only about the users' needs and how the design be used, but } \\
\text { also more broadly the social, political and/or environmental context. The } \\
\text { student designers in this category tried to take the perspective of the user when } \\
\text { designing, but discussed doing that more in theory as to how it should be, } \\
\text { lacking the emphasis of "needing to be" that comes as a result of an experience } \\
\text { that challenged their understanding. The design was integrated to the extent } \\
\text { allowed by the student designers' disciplinary knowledge. }\end{array}$ \\
\hline $\begin{array}{l}\text { Category 6: } \\
\text { Commitment } \\
\text { to Involving } \\
\text { Stakeholders } \\
\text { to Understand } \\
\text { Perspectives }\end{array}$ & $\begin{array}{l}\text { to involving stakeholders in the } \\
\text { ectives, seeking and taking into } \\
\text { balancing multiple perspectives. } \\
\text { sibility and viability } \\
\text { though the degree in which they are } \\
\text { ence. }\end{array}$ \\
\hline $\begin{array}{c}\text { Category 7: } \\
\text { Empathic } \\
\text { Design }\end{array}$ & $\begin{array}{l}\text { Human-centered design is Empathic Design, basing design on knowledge } \\
\text { gained through a connection with end users, not on preconceived ideas and } \\
\text { assumptions. The student designers in this category developed a very broad } \\
\text { understanding of stakeholders beyond scope of project, interacting with users } \\
\text { informally and in social situations. They sought and took into consideration } \\
\text { contextual information, as well as how it will be used and what the user needs. } \\
\text { This approach integrates desirability, feasibility and viability } \\
\text { requirements/perspectives into design. }\end{array}$ \\
\hline
\end{tabular}

We primarily focused on the B1 table of activities in the design task and any additional sketches or responses provided on the blank page. While the responses to the open-ended questions (B1 B5) yielded additional insights to better understand the students' responses, the five questions themselves introduced some bias towards a more-comprehensive understanding of humancentered design, as discussed in the pilot study ${ }^{[17]}$. Therefore these responses were not considered as trustworthy as the table responses.

We assumed that the students approached the design task from beginning to end with little to no correction or addition to previous sections once completed. The design task was assembled with problem description, blank space, the table of activities, and five open-ended questions, the last of which is for respondents to tell a story about significant design experiences that influenced them. Our assumption is based upon most responses in Question 4 saying that the designers would ask parents, children, and experts "tons of questions" "throughout the design process" that were not substantially included in the table of activities one section before. 


\section{Analysis and Results}

Table 3 and Figure 1 below list the pre-camp and post-camp design task categories for each of the students who participated in this course. Discussion follows on the qualitative data in the design task that led us to the Design Category values for each response.

Table 3. Pre and post camp experience Design Categories for participants.

\begin{tabular}{|l|l|c|l|}
\hline Pseudonym & Pre-Camp Category & Post-Camp Category & Change \\
\hline CR01 & 1 & N/A & \\
\hline CR02 & 6 & 7 & +1 \\
\hline CR03 & 4 & 6 & +2 \\
\hline CR04 & 1 & 6 & +5 \\
\hline CR05 & 6 & 6 & 0 \\
\hline CR06 & 5 & 6 & +1 \\
\hline CR07 & 5 & 4 & -1 \\
\hline CR08 & 3 & 5 & +2 \\
\hline CR09 & 4 & 4 & 0 \\
\hline CR10 & 3 & 4 & +1 \\
\hline CR11 & 3 & 5 & +2 \\
\hline CR12 & 5 & 6 & +1 \\
\hline CR13 & 1 & 4 & +3 \\
\hline
\end{tabular}

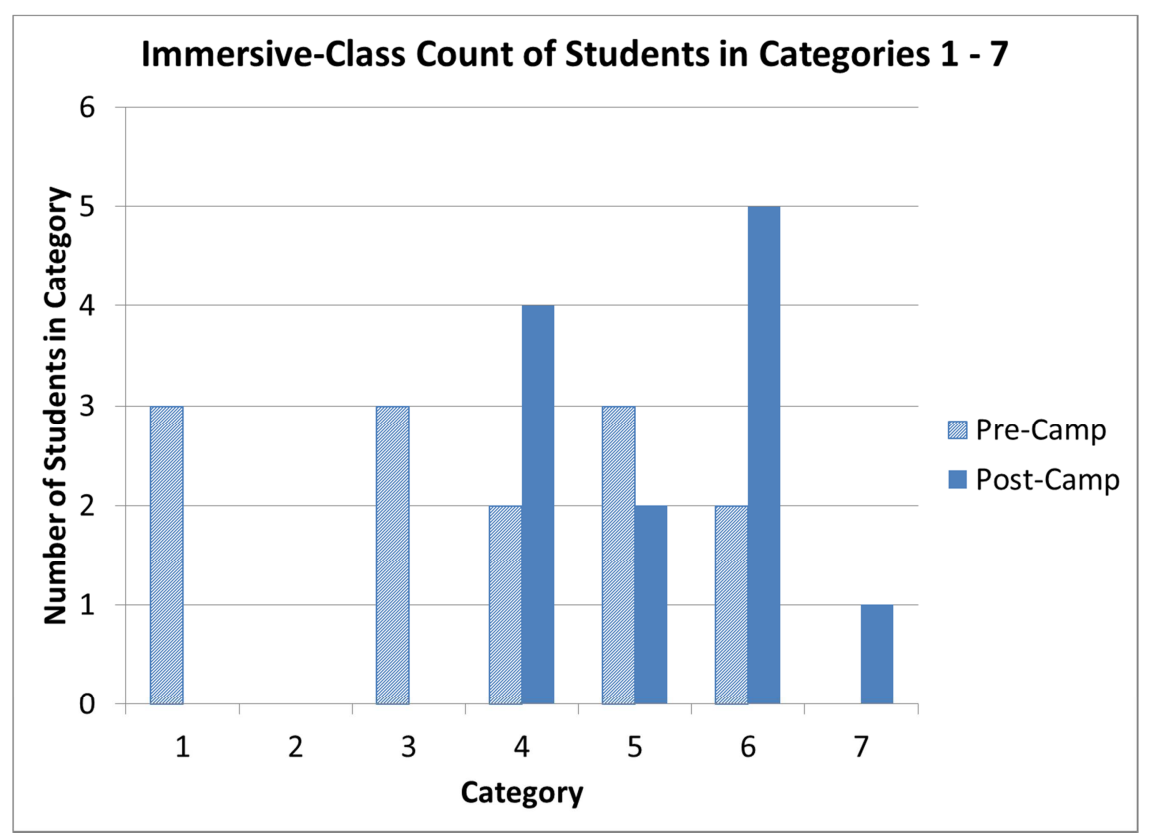

Figure 1. Counts of students in design categories pre-camp and post-camp experience.

In order to determine a statistically significant difference between the pre-camp and post-camp categorizations, we used the Wilcoxson Signed Rank Test ${ }^{[20]}$. It is similar to a t-test because of operating on a small sample size. This is appropriate because of the following assumptions and characteristics that differ from a t-test: the data are paired values that are independently drawn; the values are on an ordinal scale; and there may not be a normal distribution around the mean 
value (non-parametric). This test allows for the use of the normal distribution table for determining significance. The Wilcoxson Signed Rank Test for the paired data shows an $\alpha$ significance of 0.006 . For this calculation, we include the 12 pairs of data and exclude the participant who did not complete a post-camp design task. The analysis shows a statistically significant difference between the pre-camp and post-camp categories of the participants.

\section{Qualitative Analysis}

The pre-camp design task data, described in the B1 table of activities, suggest the recognition that the end users and stakeholders should be included, though the respondents do not have a solid plan for their inclusion. The vocabulary used was frequently "show the prototype to stakeholders". The design process is very much centered on the soapbox derby car, but not the total race experience or any other activity. The lower Category individuals tend to list only design team members as the people involved in design, especially itemized in question B3.

The post-camp design task data, described in the B1 table of activities, suggest that the respondents developed solid plans to identify and include stakeholders at the beginning of the design process for problem framing and specification development. The respondents include data collection methods of observation and interview of stakeholders. The respondents changed their vocabulary from "show the prototype" to "get feedback" from the stakeholders and to test the prototype with users, suggesting a change in attitude toward the role that stakeholders can play in design. At least two respondents included emotional and social items like "doing something you normally can't do" and "make new friends" as part of the total race experience. However, very few respondents specifically listed observation outside of race activities in the post-camp soapbox derby design task data, which would indicate Category 7 design thinking.

Question 1 of the design task questionnaire is "as a designer, what do you feel is important to consider when doing design, and why?" The most common answer here for the students who have participated in our community engagement program is "consider the stakeholders" or "stakeholder needs" or "user needs". The other common answers are safety, reliability, quality, and cost. However, respondents often neglect to list engagement with stakeholders in the B1 table of activities. Because of the lack of stakeholder engagement in the table of activities, we rated these responses as lower categories 1 and 3 .

Question 3 of the design task questionnaire is "list all the people who would have a role in the design process. For each, describe why they would be involved". Category 1 individuals listed just the design team in this question. Category 3 and 4 individuals listed project partners, experts, and advisors in addition to the design team. The data suggests that most of the postcamp respondents can now provide detailed lists of stakeholders, including children, parents, drivers, race organizers, spectators, donors, government agencies, mechanics, and materials suppliers. The longer list of stakeholders indicates an increased awareness of the larger social context of design.

Question 5 of the design task questionnaire is "describe any design experiences that influenced how you approached this design, and how it influenced you". The pre-camp Category 6 individuals provided a story of a design project with particular users with whom they interacted. 
The post-camp responses, with the exception of CR07, list this course experience as the main influence for their approach to design.

Question 2 of the task questionnaire is "what does it mean to design well? How do you measure success?" This question was mostly answered by pointing back to the answer to Question 1, so it did not provide substantial new information. Question 4 of the design task is "if you had unlimited access to children, parents, experts, etc., how would you include each in the design process and what information would you want to learn from each?" The question was generally answered with only the persons itemized in the question and each was generally asked what their opinions are, so these answers did not provide substantial new information in comparison to Question 3.

\section{Discussion}

The main expectation is that the students in the summer session increased their understanding of human-centered design as a result of the immersive design experience at the camp and therefore would be categorized higher on the post-camp design task than the pre-camp design task. In the post-camp design task responses we expect to see more engagement with stakeholders at the beginning of the design process to include problem definition and specification development. We also expect to see an increase in iteration with the users and other stakeholders in prototyping and testing. Finally, since the time spent at the camp with campers included observation and interaction in activities unrelated to the treehouse and sailboat projects, we expect to see inclusion of such activities in order to gain a deeper understanding of users.

This analysis of design task responses shows that an immersive experience with users increases the student designers' awareness of users' needs, reduces designers' propensity for making assumptions, and increases designers' use of a rigorous iterative design process. This confirms the expectations of increasing involvement of the stakeholders and simultaneous increasing understanding of design. However, we did not find that students generally listed observation and interaction with stakeholders in informal settings as part of the design process, which is what the students did at camp. While only one student made an impressive five category leap from Category 1 to 6 in only three weeks, it is encouraging that the students generally moved up as a result of this immersive experience.

One student appears to have moved backward in understanding of design and inclusion of stakeholders. It appears that the list of stakeholders between pre-camp and post-camp experience became less descriptive. This is unusual. One explanation could be fatigue at the end of an intense course but there is not a sound way of gauging the effect of fatigue.

An alternative explanation for the apparent lack of Category 7 evidence is that the soapbox derby design task aligns so well with the treehouse and sailboat projects of the immersive course that the respondents may feel that they already know the users and do not have to include the step of understanding the user in this design task. A second alternative explanation for the apparent lack of Category 7 evidence is that the soapbox derby design task as a measurement tool is limited in its ability to elicit Category 7 thinking. The responses to the reflection questions B6 and B7 from the students have indications of Category 7 understanding of design as acknowledged by 
the participants themselves; however, we did not include qualitative analysis of the reflection questions in this paper. Further evidence is included in another publication, however, that the students are moving toward empathic design thinking ${ }^{[9]}$.

\section{Future Directions}

A rubric is in development to evaluate the soapbox derby design task based on the phenomenographic framework. Characteristics such as whether and how the users and stakeholders are engaged, types of information about users considered by the designers, and the level of iteration in the design process gave indication to which Category the design task fits. The higher Category design task data from this work will also inform this rubric. This may assist future non-research users of the design task in categorizing students' understanding of design.

The rubric will contain the commonly included evidence of each of the categories. Category 3 individuals show engagement with the stakeholders at the beginning of the table, with the subsequent steps generally being design - build - test-deliver. Category 4 individuals generally show an iteration of prototype - test with user - refine-deliver. A detailed list of stakeholders is in Question 3; we were specifically looking for stakeholders beyond the design team, children, and parents in order to identify Category 5 or higher individuals (however, if students responses to the B1 table were generally consistent with Category 1 or Category 2, the response was categorized as a 1 or a 2 even if a diverse group of stakeholders was listed for Question 3). Specific stories appear in Question 5 as an indicator of Category 6 or higher individuals who had specific experiences that caused them to confront their assumptions about the stakeholders (with the same caveat as described for Category 5/ Question 3). We looked for a change in language for Category 6 and 7 respondents who said "stakeholder feedback is critical to our success" and could explain what would happen to the design if they did not include such feedback. Category 7 individuals include the observation and interaction with users and stakeholders in informal settings that are not specific to the design project as a step in the table.

\section{Conclusions}

Our findings suggest that even short immersive experiences can have a large impact on students' understanding of design. This short immersive experience showed significant increase in student understanding of design and the role of users and stakeholders. The impact may compare in impact to longer-term design experiences such as global design teams or internships that are available in limited quantities to undergraduate students. Internships and global design experiences can and do move participants toward empathic design ${ }^{[15]}$. Immersive experiences can be added to the portfolio of options available to students to allow a greater participation in such transformational experiences.

The educational implication of the findings is that a short-term ( 3 week), fairly local (1.5 hour drive), economical (\$300), immersive experience can move participants toward empathic design. Therefore we plan to continue this course and we recommend that other programs interested in helping students to develop human-centered design skills consider developing immersive service-learning design experiences as well. 


\section{Acknowledgments}

The authors would like to thank Briana Dorie for her feedback on this paper.

\section{Bibliography}

[1] C. J. Atman, R. S. Adams, M. E. Cardella, J. Turns, S. Mosborg and J. Saleem, "Engineering Design Processes: A Comparison of Students and Expert Practitioners," Journal of Engineering Education, pp. 359 - 379, 2007.

[2] ABET, "Engineering Criteria 2000: Criteria for accrediting programs in engineering in the United States, 3rd ed," 2000. [Online]. Available: http://www.ele.uri.edu/faculty/daly/crite- ria.2000.html.

[3] National Academy of Engineering, "The Engineer of 2020: Visions of Engineering in the New Century," National Academies Press, Washington DC, 2004.

[4] L. Shuman, M. Besterfield-Sacre and J. McGourty, "The ABET "Professional Skills" - Can They Be Taught? Can They Be Assessed?," Journal of Engineering Education, pp. 41-55, 2005.

[5] H. Passow, "Which ABET Competencies Do Engineering Graduates Find Most Important in their Work?," Journal of Engineering Education, pp. 95-118, 2012.

[6] J. Duffy, "Village Empowerment: Service-Learning with Continuity," International Journal for Service Learning in Engineering, pp. 1-17, 2008.

[7] J. D. Thompson and B. K. Jesiek, "Work in Progress - Project-Based Service Learning in Engineering: Investigating Partner Relationships," in 2011 Frontiers in Education Conference Proceedings, Rapid City, SD, 2011.

[8] C. B. Zoltowski, W. C. Oakes and M. E. Cardella, "Students' Ways of Experiencing Human-Centered Design," Journal of Engineering Education, pp. 28-59, 2012.

[9] C. B. Zoltowski, A. Cummings and W. C. Oakes, "Immersive Community Engagement Experience," in 2014 Annual ASEE Conference Proceedings, Indianapolis, IN, 2014.

[10] IDEO, "Human Centered Design Toolkit 2nd Edition," IDEO, 2009.

[11] S. Jordan, M. Lande, M. Cardella and H. Ali, "Out of Their World: Using Alien-Centered Design for Teaching Empathy in Undergraduate Design Courses," in 2013 Frontiers in Education Conference Proceedings, Oklahoma City, OK, 2013.

[12] C. B. Zoltowski, W. C. Oakes and M. E. Cardella, "Teaching Human-Centered Design with Service-Learning," in 2010 Annual Conference and Exposition, Louisville, KY, 2010.

[13] N. Cross, "Expertise in design: an overview," Design Studies, pp. 427-441, 2004.

[14] D. P. Crismond and R. S. Adams, "The Informed Design Teaching and Learning Matrix," Journal of Engineering Education, pp. 738-797, 2012.

[15] C. B. Zoltowski, "Students' ways of experiencing human-centered design (doctoral dissertation). Retrieved from ProQuest Dissertations \& Theses Database. (3413917).," 2010.

[16] C. B. Zoltowski, W. C. Oakes and M. E. Cardella, "Phenomenographic Study of Human-Centered Design: Educational Implications," in 2011 Annual Conference and Exposition, Vancouver B.C. Canada, 2011.

[17] R. B. Melton, M. E. Cardella, W. C. Oakes and C. B. Zoltowski, "Development of a Design Task to Assess Students' Understanding of Human-Centered Design," in 2012 Frontiers in Education Conference Proceedings, Seattle, WA, 2012.

[18] R. Melton, M. Cardella, W. Oakes and C. Zoltowski, "Assessing the Impact of Service-Learning on First-Year Engineering Students' Understanding of Human-Centered Design," in 2013 IEEE Frontiers in Education Conference, Oklahoma City, OK, 2013.

[19] T. Both, "Design Resources: The Wallet Project," 10 October 2013. [Online]. Available: https://dschool.stanford.edu/groups/designresources/wiki/4dbb2/. 
[20] R. Lowry, "Concepts \& Applications of Inferential Statistics," 2013. [Online]. Available: http://vassarstats.net/textbook/index.html. [Accessed 10 February 2014].

\section{Appendix A - Survey of Participants}

1. What is your major (no acronyms please)?

2. What is your classification (Freshman, Sophomore, Junior, Senior, or Graduate student)?

3. How many semesters have you completed as a college student?

4. Please list any courses you have taken that taught design or the design process.

5. Briefly list any experiences where you participated in design, if any.

6. How many semesters have you participated in our community engagement program, including this one? 


\section{Appendix B - Design Task}

\section{Scenario Description}

It is the first day of the fall term. You are the team leader of a design team that will be delivering a finished project this semester. Your team has designed a new Soap Box Derby car that opens the event to children who have physical and cognitive disabilities by allowing a professional driver to ride in a backseat and maintain full control of the car. Soapbox derby cars are towed to the top of a small hill and they "race" by coasting down the hill on a straight track. While there are no turns in the course, the cars have steering to maintain control of the cars. In a traditional Soap Box Derby car, the child is by him or herself and steers the car. By allowing an adult to ride in a backseat and maintain full control of the car your team has enabled children to participate in the Soap Box Derby event who previously could not have done so safely.

Your team has studied other designs for children with disabilities and these designs either have no steering for the child in the front seat or they have added spring tension to the child's steering wheel in order to simulate the feeling of driving and make the child's experience more realistic and fun. In either case the child cannot actually control the car, the child only has the illusion of control.

The question has been raised if the design should allow children who are capable of steering to do so with the driver being able to override the child. The information that you have at this point does not point in one direction or another. Your team's advisor confesses that she/he is not an expert in this area and has deferred to the team to determine the best design. Your advisor has stressed, however, that the new design has to be finished this semester. As the team leader, you are asked to develop a plan to get the design right and to make sure it is finished this semester (or quarter).

Fill out the table given to describe, in detail, the activities to be completed during this term leading up to delivery of a finished project. Include the specific design decisions you would make and the different roles your teammates would take.

The blank space provided on the following pages is for you to use as you see fit. You can create a visual representation (flow chart, flow diagram, Gantt chart, or other picture) to show the sequencing and/or relationships of the activities or simply use to get your thoughts together.

[Blank page provided for the student's use] 
Table B1. Soapbox Derby Design Task - table of activities.

\begin{tabular}{|l|l|l|l|}
\hline $\begin{array}{l}\text { List the activities to } \\
\text { be completed during } \\
\text { the semester. (List } \\
\text { activities } \\
\text { individually). }\end{array}$ & $\begin{array}{l}\text { What resources and/or } \\
\text { people would be } \\
\text { involved? }\end{array}$ & $\begin{array}{l}\text { How would those } \\
\text { resources and/or } \\
\text { people be involved? }\end{array}$ & $\begin{array}{l}\text { Why is the activity } \\
\text { being done? What is } \\
\text { the purpose of doing } \\
\text { the activity? }\end{array}$ \\
\hline & & & \\
\hline
\end{tabular}

Please answer the following questions.

B1) As a designer, what do you feel is important to consider when doing design, and why?

B2) What does it mean to do design well? How do you measure success?

B3) List all the people who would have a role in the design process. For each, describe why they would be involved.

B4) If you had unlimited access to children, parents, experts etc., how would you include each in the design process and what information would you want to learn from each?

B5) Describe any design experiences that influenced how you approached this design, and how it influenced you.

Post-Camp Reflection Questions

B6) How have your responses changed (to the task and to the reflection questions)?

B7) What would you attribute the change to? 